\title{
The potential for sustainability of malaria in pregnancy initiatives in East and Southern Africa: Kenya and Malawi
}

Washington Onyango-Ouma

Sam Agatre Okuonzi

Doreen Ali

Harriet Birungi

Population Council

Annie Mwangi

Population Council

Follow this and additional works at: https://knowledgecommons.popcouncil.org/departments_sbsr-rh

Part of the International Public Health Commons, Maternal and Child Health Commons, Parasitic Diseases Commons, and the Social and Behavioral Sciences Commons

How does access to this work benefit you? Let us know!

\section{Recommended Citation}

Onyango-Ouma, Washington, Sam Agatre Okuonzi, Doreen Ali, Harriet Birungi, and Annie Mwangi. 2008. "The potential for sustainability of malaria in pregnancy initiatives in East and Southern Africa: Kenya and Malawi," FRONTIERS Final Report. Washington, DC: Population Council. 


\title{
The Potential for Sustainability of Malaria in Pregnancy Initiatives in East and Southern Africa: Kenya and Malawi
}

\author{
Institute of African Studies, University of Nairobi, Kenya \\ W. Onyango-Ouma \\ Regional Center for Quality of Health Care \\ Institute of Public Health, Makerere University \\ Sam Agatre Okuonzi \\ National Malaria Control Program, Malawi \\ Doreen Ali
}
Frontiers in Reproductive Health Program, Population Council, Kenya Harriet Birungi
Annie Mwangi

June 2008

This study was possible through the generous support of the people of the United States through the United States Agency for International Development (USAID), under the terms of Cooperative Agreement No. HRNA-00-98-00012-00 and In-house project 8012 53905. The contents are the responsibility of the FRONTIERS Program and do not necessarily reflect the points of view of USAID or the United States Government.
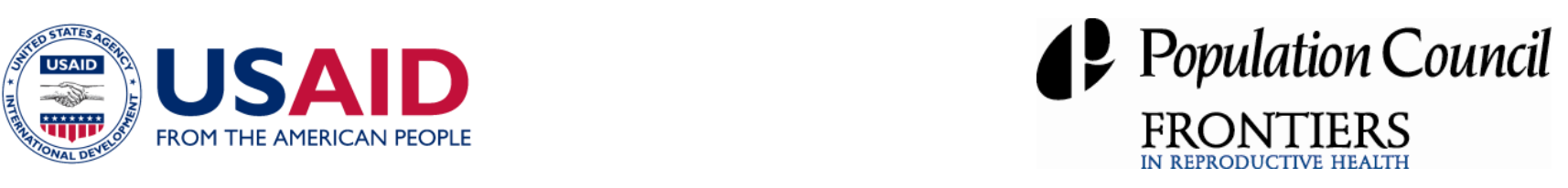
(C) 2008 The Population Council, Inc.

Suggested citation: Onyango-Ouma, W., Sam Agatre Okuonzi, Doreen Ali, Harriet Birungi, and Annie Mwangi. 2008. "The potential for sustainability of malaria in pregnancy initiatives in East and Southern Africa: Kenya and Malawi," FRONTIERS Final Report. Washington, DC:

Population Council.

Any part of this publication may be reproduced without permission for limited distribution provided it is distributed without charge and the Population Council is acknowledged as the source. The Population Council would appreciate receiving a copy of any materials in which the text is used. 


\section{CONTENTS}

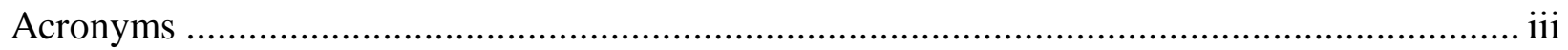

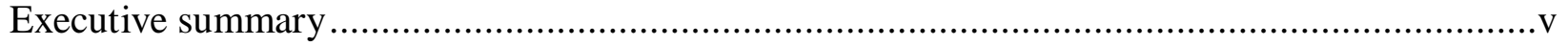

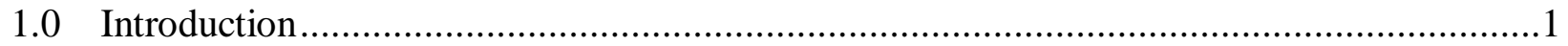

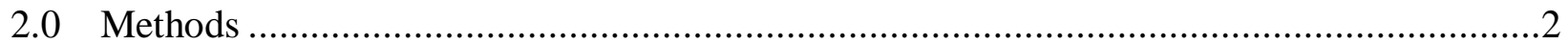

2.1. Data collection ...................................................................................2

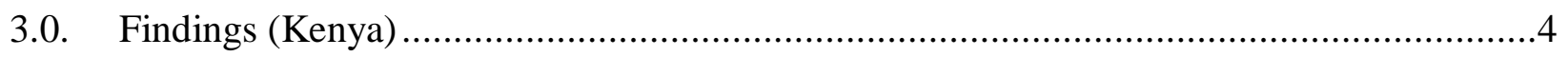

3.1. Sustainability of malaria in pregnancy interventions ...................................4

3.2. Malaria in pregnancy interventions beyond the project district .......................... 8

3.3. Key factors for sustainable interventions ...................................................... 11

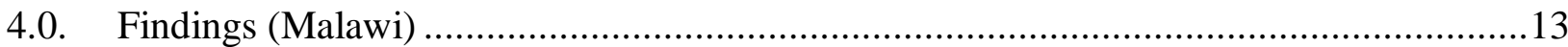

4.1 Continuation of MIP Interventions in Blantyre district ..................................13

4.2. MIP activities beyond Blantyre District..................................................... 14

4.3. Capacity and viability of the district health system to sustain services .................15

4.4. Best Practices from BIMI........................................................................20

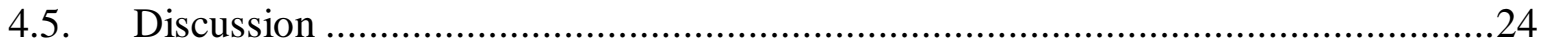

5.0 Lessons learnt and Conclusions from Kenya ............................................................26

6.0. Lessons learnt and conclusions from Malawi .........................................................28

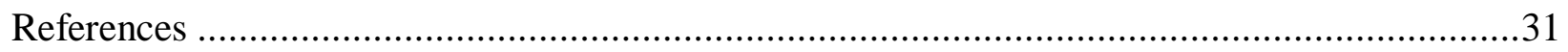




\section{ACRONYMS}

\begin{tabular}{|c|c|}
\hline AIDS & Acquired Immunodeficiency Syndrome \\
\hline AIMI & Africa Integrated Malaria Initiative \\
\hline AMREF & African Medical and Research Foundation \\
\hline ANC & Antenatal care \\
\hline BDMI & Bungoma District Malaria Initiative \\
\hline BIMI & Blantyre Integrated Malaria Initiative \\
\hline BUCHO & Bungoma Community Health Organization \\
\hline $\mathrm{CDC}$ & Centers for Disease Control and Prevention \\
\hline CMS & Central Medical Stores \\
\hline COMESA & Common Market of East and Southern Africa \\
\hline CORP & Community Owned Resource Person \\
\hline CSSA & Child Survival Sustainability Assessment \\
\hline DFID & Department for International Development (of the UK) \\
\hline $\mathrm{DHO}$ & District Health Officers \\
\hline DHMT & District Health Management Team \\
\hline $\mathrm{DMOH}$ & District Medical Officer of Health \\
\hline DOT & Directly Observed Treatment \\
\hline EARN & East African Rollback Malaria Network \\
\hline EHP & Essential Health Package \\
\hline $\mathrm{EU}$ & European Union \\
\hline GOM & Government of Malawi \\
\hline $\mathrm{HC}$ & Health Center \\
\hline HIV & Human Immunodeficiency Virus \\
\hline HRD & Human Resource Department \\
\hline HSAs & Health Surveillance Assistants \\
\hline IPT & Intermittent Presumptive Treatment \\
\hline IEC & Information, Education and Communication \\
\hline IGA & Income Generating Activities \\
\hline IMCI & Integrated Management of Childhood Illnesses \\
\hline ITN & Insecticide Treated Net \\
\hline JICA & Japan International Cooperation Agency \\
\hline $\mathrm{JKJ}$ & Jirani-kwa-jirani \\
\hline LBW & Low Birth Weight \\
\hline KDHS & Kenya Demographic and Health Survey \\
\hline KES & Kenyan Shilling \\
\hline KSPA & Kenya Service Provision Assessment \\
\hline $\mathrm{MOH}$ & Ministry of Health \\
\hline
\end{tabular}




$\begin{array}{ll}\text { MOU } & \text { Memorandum of Understanding } \\ \text { MIP } & \text { Malaria in Pregnancy } \\ \text { NGO } & \text { Non-Governmental Organization } \\ \text { PMPB } & \text { Pharmacy, Medicines and Poisons Board } \\ \text { PSI } & \text { Population Services International } \\ \text { QAP } & \text { Quality Assurance Project } \\ \text { RBM } & \text { Roll Back Malaria } \\ \text { REDSO } & \text { Regional Economic Development Services } \\ \text { RHU } & \text { Reproductive Health Unit } \\ \text { SC } & \text { Steering Committee } \\ \text { SP } & \text { Sulfadoxide-pyrimethamine } \\ \text { SWAP } & \text { Sector Wide Approach } \\ \text { TBA } & \text { Traditional Birth Attendant } \\ \text { UNICEF } & \text { United Nations Children's Fund } \\ \text { USAID } & \text { United States Agency for International Development } \\ \text { VTV } & \text { Vendor-to-Vendor } \\ \text { WHO } & \text { World Health Organization } \\ \text { WVI } & \text { World Vision International }\end{array}$




\section{EXECUTIVE SUMMARY}

Malaria infection in pregnancy is a major public health problem in tropical and subtropical regions throughout the world. In most malaria-endemic areas of Africa, women in their first and second pregnancies have the highest risk of acquiring malaria and consequently of increasing malaria-associated anemia and Low Birth Weight (LBW). The Bungoma District Malaria Initiative (BDMI) project and the Blantyre Integrated Malaria Initiative (BIMI) sought to improve maternal and child health survival by preventing and treating illness from malaria. Both projects introduced two strategies to strengthen prevention and management of malaria in pregnancy: (1) giving Intermittent Presumptive Treatment (IPT) of Sulfadoxide-pyrimethamine (SP) during women's Antenatal Care (ANC) visits; and (2) promoting the use of Insecticide Treated Nets (ITNs) by pregnant women.

This study assesses the sustainability of this initiative, documents best practices for promoting sustainability, and draws lessons for replication in other East and Southern African countries where malaria is endemic. The study applied the Child Survival Sustainability Assessment (CSSA) framework to analyze progress toward sustainability, which included not only a biomedical perspective but also the human, social, and organizational processes that influence sustainability of health projects. In both Kenya and Malawi, data were collected through document reviews, situation analysis of health facilities, key informant interviews, and community interviews with randomly selected women who had been pregnant in the preceding year. The key findings for both countries were as follows.

Malaria in Pregnancy (MIP) interventions have been sustained within and beyond the project districts. IPT and ITNs are still being offered in project districts at both public and private facilities. District coverage for IPT and ITNs has increased since the end of both projects, and these services have been incorporated into the district annual plans and budgets, guaranteeing their sustainability. The BDMI built the capacity of the District Health Management Team (DHMT) to sustain these MIP interventions through heavy investment in training district personnel in planning, coordination, monitoring, and evaluation. Although some of the staff have since been transferred, on-the-job training has been organized for new staff. On the other hand, the BIMI was conceived to be implemented through existing structures and it became embedded into and part of the national health system. Its activities started in one district, expanded to all districts, and continued after BIMI officially ended.

Both BDMI and BIMI contributed to change in national policies by providing evidence supporting the adoption of IPT and ITN as routine services to be offered during ANC consultations. The BDMI successfully advocated for the adoption of SP as the first-line antimalarial treatment and lobbied for SP to be removed from the list of prescription-only drugs. SP is now available over the counter, making it possible for small businesses to stock and distribute it. The pro-poor approach to ITN distribution developed and tested under BDMI was also included in the national ITN policy.

Key processes critical to the development of sustainable MIP interventions include: (1) integration of MIP services into the existing health system and a clear human resource development strategy; (2) development of evidence-based best practices for policy change and 
practice; (3) capacity building for local groups; (4) fostering public-private partnerships; and (5) building capacity for resource mobilization.

\section{Key lessons from Kenya include:}

- Importance of clearly defining the roles of partners.

- Adequate funding for both introducing and testing interventions.

- Integration of interventions into the existing health system.

- The initiatives must provide clear leadership and coordination.

- A strong human resource development strategy.

- Empowering local communities to participate.

- A research component to provide evidence of success.

\section{Key lessons from Malawi include:}

- A persistent and systematic approach to problem-solving.

- Evidence-based health policies supported by a strategic partnership and complementary economic policies, such as ITN subsidies.

- Donors are better convinced by what works rather than with ready-made solutions. They are more inclined to support a policy in which they have participated and with which they agree.

- A successful project should be sustained and scaled up by integration into the national healthservice delivery system. 


\subsection{INTRODUCTION}

Malaria infection during pregnancy remains a major public health problem in tropical and subtropical regions throughout the world. In most malaria endemic areas of Africa, pregnant women are the main adult group at risk for malaria, for whom the principal outcome is malariarelated anaemia ${ }^{1}$ in the mother and the presence of parasites in the placenta. Placental malaria and maternal anaemia are risk factors for spontaneous abortion and Low Birth Weight (LBW), which in turn, is the highest single factor for neonatal and infant mortality. In malaria endemic areas, moreover, it is women in their first and second pregnancies that have the highest risk of acquiring malaria and consequently of increasing malaria-associated LBW in their infants. Maternal malaria contributes 3 percent to 8 percent of the infant mortality (Steketee et al. 2001). Despite the toll that malaria exerts on pregnant women and their infants, this was until recently a relatively neglected problem, with less than 5 percent of pregnant women having access to effective interventions (WHO 2003). However, feasible and cost effective strategies for prevention and control of malaria in pregnancy have now been developed, namely Insecticide Treated Nets (ITN) and Intermittent Presumptive Treatment (IPT) with Sulfadoxidepyrimethamine (SP) (Parise et al. 1998; Goodman, Coleman, and Mills 2001).

In 1998 through 2004, United States Agency for International Development (USAID)/Washington provided funding through their missions in Malawi and Kenya to support the Africa Integrated Malaria Initiative (AIMI) to implement malaria control programs in each country; these programs included special initiatives focusing on Malaria in Pregnancy (MIP). The initiative explored programmatic interventions for reducing morbidity and mortality among pregnant women and sought to strengthen local capacity to deliver effective, integrated, and sustainable malaria control at the health facility level. Among projects supported through this initiative were the Blantyre Integrated Malaria Initiative (BIMI) in Malawi and the Bungoma District Malaria Initiative (BDMI) in Kenya.

The BDMI was a district wide project implemented for a five-year period (1998-2002) with a budget of approximately US\$5 million that sought to improve maternal and child health survival by preventing and treating illness from malaria. As with the BIMI, two intervention strategies were introduced to address prevention and management of malaria in pregnancy: (1) giving IPT during women's Antenatal Care (ANC) visits; and (2) promoting the use of ITNs by pregnant women. The Kenyan partners implementing the BDMI were the Ministry of Health (MOH) through the Bungoma District Health Management Team (DHMT) and the African Medical and Research Foundation (AMREF). The USAID-funded Quality Assurance Project (QAP) of the Centers for Disease Control and Prevention (CDC) provided technical assistance.

The BIMI was a US\$5.8 million district wide malaria control effort supported jointly by the Government of Malawi (GOM), USAID, and the CDC. The project had four main objectives, with two of these focusing on MIP: (1) improving access and demand for IPT among pregnant women using SP; and (2) increasing demand, access for, and appropriate use of affordable ITNs. The project was completed in early 2004 and has subsequently continued to provide support to the national malaria prevention and control program in developing the country's strategic plan

1 Seven percent of severe anaemia in pregnancy in Sub-Saharan Africa is due to malaria. 
for Roll Back Malaria (RBM) the national malaria policy, and guidelines for managing the ITN Program and participating in other national program activities.

This study was commissioned by USAID/REDSO to assess the sustainability of the MIP activities developed during the BDMI, document best practices for sustainability, and draw lessons for replication in other East and Southern African countries where malaria is endemic. Specifically, it sought to:

- Determine the extent to which activities of malaria in pregnancy interventions implemented through BDMI have continued after the project period.

- Assess the extent to which malaria in pregnancy interventions has achieved a scale beyond the project district.

- Identify key processes and/or factors that are critical in developing sustainable MIP interventions.

- Draw lessons for other countries in the region that are currently or intending to implement MIP strategies.

\subsection{METHODS}

A case study method was used based on the Child Survival Sustainability Assessment (CSSA) framework (Sarriot et al. 2004). The CSSA was developed for mapping progress toward sustainable projects from the community level and upward. The framework includes a biomedical perspective as well as the human, social, and organizational processes that influence sustainability of health projects. The CSSA framework is organized around three interrelated dimensions:

1) Health and health services: The outcomes, such as ITN and IPT coverage, that stakeholders want to sustain, as well as the conditions needed for sustainability.

2) Capacity and viability of the local organization: The capability needed to maintain the essential services and activities and the viability of financial and other essential types of support and relationships.

3) Capacity of the community: Elements (e.g., national and regional policies) outside the project's scope of intervention, and conditions in the districts in which the interventions were implemented, that have enabled progress to be maintained.

\subsection{Data collection}

Data collection was undertaken between February and June 2006 using the following methods:

Document review: In both countries, a desk-based appraisal of key documents was undertaken to collect data on all three dimensions of sustainability. Midterm and annual review reports, interim working reports, independent study reports, program documents, and local publications were assembled and reviewed for their content in relation to sustainability perspectives. The Kenya Service Provision Assessment (KSPA) was reviewed for quantitative data that reflect the 
scale of MIP, including the availability, accessibility, and coverage of MIP services across Kenya. The Kenya Demographic and Health Survey 2003 (CBS, MOH, and ORC Macro 2004) was also reviewed to assess the extent to which pregnant women in Kenya have adopted IPT and ITN practices in general. For Malawi, the Demographic and Health Survey 2000 (National Statistical Office and ORC Macro 2000) was reviewed for baseline assessment of the scale of MIP. A number of publications on the successes of MIP initiatives were reviewed to decipher the sustainability and scale-up factors. In particular, the report by the MOH National Malaria Survey (MOH 2004c) provided vital information.

Facility analysis: This included an assessment of the sustainability of relevant health system components (e.g. training and commodity supplies) at the facility level. In Kenya, the analysis covered a representative sample of 45 facilities in the Bungoma district offering ANC, including hospitals, health facilities, dispensaries, and private facilities. In Malawi, the analysis covered a representative sample of 29 facilities in the Blantyre district offering ANC, including 20 government-owned facilities, 4 private facilities, and 2 faith-based facilities. The analysis measured the extent to which the MIP practices have continued in the facilities. The facility analysis included interviews with the clinic in charge and with MIP-trained providers, and a review of clinic registers for service statistics. Clinic records were also reviewed to see whether there was a trend over time regarding MIP services.

Community survey: In both countries, a community survey was undertaken to establish whether the women had received SP and slept under ITNs during their last pregnancy. ANC/maternal health cards were also reviewed for the same. In Kenya, interviews using structured questionnaires were administered to 330 women, randomly selected from the 109 sub locations in the district, who had delivered in the last 6 months. To ensure representativeness, $30 \mathrm{sub}$ locations were randomly selected from the 109 sub locations in the district. Thereafter, 11 women who had delivered in the last 6 months were randomly selected from each of the $30 \mathrm{sub}$ locations. This gave a sample size of 330 women, similar to the number used in the 2002 final evaluation, making comparison of findings easier. In Malawi, interviews were administered to 401 women, randomly selected from the 31 sub locations in the district, who had delivered in the last 6 months.

Key informant interviews: The interviews described the dimensions of capacity and viability of the local organization and the capacity of the community in its social, ecological context. In Kenya, in-depth interviews were held with ten key actors, such as policy makers and program managers and consultants, at the national and district levels who had been key players in the BDMI, working with AMREF, the World Health Organization (WHO), USAID, and MOH. In Malawi, 29 key informants were interviewed, including BIMI project staff, MOH department heads, donor partners, major Non-Governmental Organizations (NGOs), district authorities, and health facility staff. The MOH informants included policy makers, program managers, and consultants. The donor partners included the World Bank, USAID, the Japan International Cooperation Agency (JICA), WHO, and the United Nation's Children's Fund (UNICEF). The NGOs included Population Services International (PSI), World Vision International (WVI), and MSH. The BIMI was piloted in the Blantyre district, and so district and project leaders were interviewed as well. 


\subsection{FINDINGS (KENYA)}

\subsection{Sustainability of malaria in pregnancy interventions}

Sustainability was defined for the BDMI in terms of the capacity of the MOH staff, and principally the DHMT, to be able to continue the activities initiated during the project after it had ended (Seltzer 2002). Key informants defined sustainability as the technical, financial, and social capacity of projects to continue after donor pull-out. This requires putting in place systems and processes to ensure that interventions continue once external support is withdrawn. Sustainability of MIP interventions in the district was measured in terms of health and health services that have been sustained, capacity and viability of the district to maintain essential intervention services, and community and social ecological conditions in the district that have enabled progress to be maintained.

\subsubsection{Health and health services}

The BDMI has been sustained in terms of health services and improved health of pregnant women, as evidenced by levels of IPT and ITN coverage, household health behaviors (sleeping under a bed net), and improved knowledge of MIP, among mothers.

IPT and ITN coverage: Of the 45 facilities surveyed, 82 percent still offer both IPT and ITNs for pregnant women during ANC. IPT coverage at the district level has steadily increased since 2002 when the BDMI ended (see Figure 1), which is impressive, although the discrepancy between receiving first and second doses of IPT implies that not all women received the recommended two doses as prophylaxis. There were no data on overall IPT coverage for the whole of the Bungoma District for 2003 and 2004 because records were not kept. The district records showed that coverage in 2005 was 21 percent.

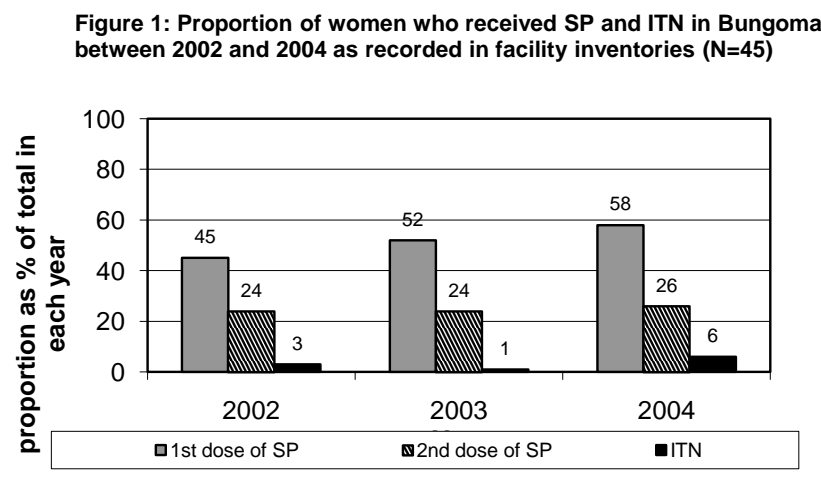

Among the 330 women who delivered in the last 6 months, 36 percent reported receiving only the first dose of SP, 33 percent received two doses, while 31 percent did not receive any SP. This was not significantly different from a survey conducted at the end of the project in 2002, which reported 32 percent of women receiving the first dose only, 34 percent received two doses, ${ }^{2}$ and 34 percent did not receive SP (Olenja, Mwanza, and Andolo 2003). SP uptake was

2 This 34 percent IPT coverage was actually below the BDMI target of 40 percent by 2002 . 
only 4 percent at baseline (1998), indicating a substantial increase. However, many clients still receive only a single dose because they attend ANC too late to qualify for the second dose. Although a single dose is better than none (because it offers limited protection), to be fully protected it is recommended that women take at least two doses.

Over half (58\%) of the 330 women reported sleeping under an ITN during their last pregnancy, which reflects a sharp increase compared with the 20 percent reported at the end of the project survey $^{3}$. However, as shown in Figure 1, the ITN coverage seems to have dropped in 2003 before picking up again in 2004. This could be attributed to the entry of a new player, PSI, which introduced cheaper nets and vigorously engaged in social marketing. PSI data shows that district ITN coverage increased significantly from an initial 6 percent in 2003, to 20.6 percent in 2004, and 24 percent in 2005.

Approximately 45 percent of the women interviewed knew that use of ITNs prevents malaria, while 69 percent knew that taking SP during pregnancy prevents malaria. These two indicators confirm that mothers possessed knowledge of MIP. This in itself may contribute to sustainability of the MIP intervention because mothers were more likely to seek services when required.

Sustainability of these health services has not been without problems, key among them being the supply of SP and ITNs, which was found to be erratic and sometimes unreliable. Health providers reported that the supply of SP since BDMI has been falling and unreliable. Although SP was available in 52 percent of the facilities on the day of the research team's visit, 71 percent of facilities had experienced stock-outs in the previous 6 months. Only 17 percent of providers felt that the supply had increased since 2002. About 60 percent of mothers felt it was easier to get SP in the community in both private pharmacies and government health facilities.

About half of the facilities reported experiencing stock-outs of ITNs in the 6 months preceding the study, and 52 percent had ITNs on the day of the visit; however, 69 percent of mothers indicated that ITNs were easily available in their community and could be found in public health facilities (65\%) and in shops/dukas (19\%).

According to $\mathrm{MOH}$ policy, MIP is included within ANC services, for which there are no user fees. The Kenya Service Provision Assessment Survey 2004 (NCAPD et al. 2005) showed, however, that 37 percent of facilities in Western Province, where the BDMI was implemented, did charge a fee for ANC, which may limit access to MIP services, especially to the very poor.

\subsubsection{Capacity and viability of the district health system to sustain services}

The DHMT, under the leadership of the District Medical Officer of Health (DMOH), has a wellestablished structure for planning and coordinating health activities in the district. It plans and coordinates implementation of MIP activities to ensure there are enough supplies and equipment. The BDMI was considered an integral part of the district health system's routine activities, which provided the opportunity for district personnel to be actively involved in implementation

${ }^{3}$ The 2002 survey data seem to differ from the facility inventory data in Figure 1 . The high percentages recorded in the survey included nets received from other sources (e.g., shops), while the inventory data is limited to facilityissued nets. 
of MIP services. Although some staff have since been transferred, two members of the DHMT who had participated actively in the BDMI were still in place, and they used their experience to coordinate activities and train new staff. Monitoring is done by the DHMT during routine supervisory visits, and MIP indicators for IPT and ITNs are part of the supervisory/monitoring checklists.

BDMI had a human resource development strategy, which saw most nurses, public health technicians, and clinical officers in the district trained and equipped with relevant skills.

Capacity building was also extended to include Community Owned Resource Persons (CORPs), Traditional Birth Attendants (TBAs), and organized community groups, who were trained on IPT and ITNs, and specifically on detection of malaria symptoms, fever management, making referrals and net re-treatment. Building the capacity of the district as a whole for the implementation of the MIP interventions was intended to create conditions for sustainability. Some training activities have been sustained after the BDMI, through government and health development partners' support, but the facility analysis found that only 41 percent of facilities had all their staff trained in IPT with SP (see Figure 2).

Figure 2: Facilities reporting proportion of health workers who have received training on prevention and treatment of malaria in pregnancy by $2006(\mathrm{~N}=45)$

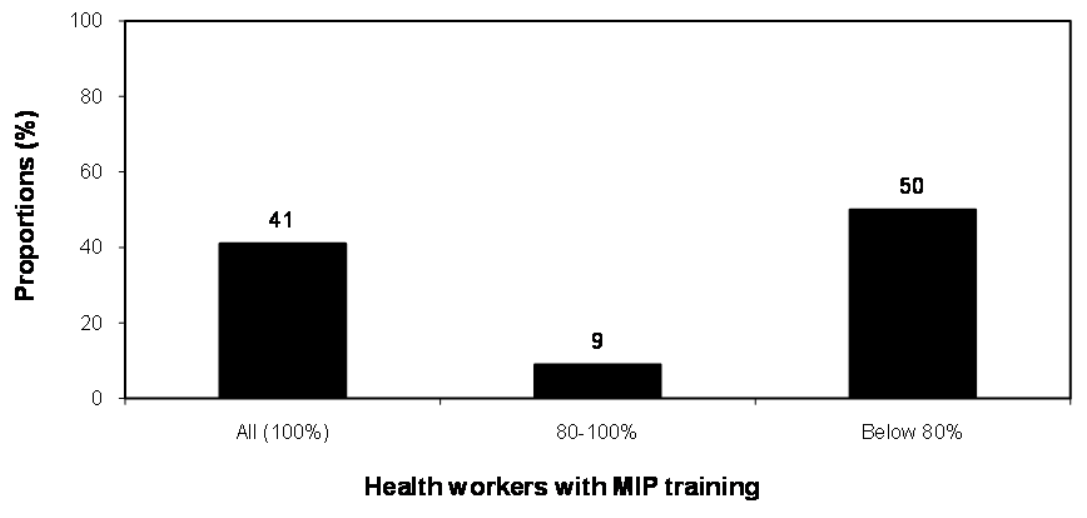

The district health system has been able to mobilize resources for sustaining the interventions and services through incorporating MIP services into the district health plans so that they receive supplies and equipment through the regular government commodity supply system. Although the SP and ITNs supplied through the government system are not sufficient and facilities often experience stock-outs, the supply is regular and sustainable. The DHMT needs to lobby for the quantity to be increased to meet the demand; this might be difficult, however, since the government does not have the financial resources to invest as heavily in the district as was done under the BDMI. A key informant observed:

"Financial sustainability is difficult to achieve because BDMI spent a lot of money that the MOH cannot plough into just one district; resources at MOH are inadequate to sustain projects." 
Resources from several health development partners (Global Fund, the Department for International Development, UK (DFID), the European Union (EU), UNICEF, WHO, and USAID $)^{4}$ have been used to meet the deficit left by the government, and this support has been instrumental in bringing down the price of ITNs through subsidies.

The BDMI fostered good working relationships with other actors, especially the private and NGO sectors. Relationships were established with private pharmaceutical companies, such as Cosmos, Aventis, and Vastegaard, which worked with BDMI and supported activities such as field days and treatment camps. They also supplied drugs at subsidized costs to drug vendors. Pharmacies also engaged in training drug vendors, as well as key wholesalers and retailers. While these groups subsidized the costs of BDMI activities, their links with the district health system and community groups seemed to have weakened with the end of the BDMI; PSI remains the only private organization with links to the district health system and community groups and supports the distribution of ITNs. The contribution of the relationships with these other groups to sustainability of MIP interventions in the district is largely unclear.

\subsubsection{Community and other external conditions}

A number of factors contributed to the sustainability of interventions, including:

- Existing community goodwill and public awareness of MIP services have harnessed community participation in MIP services.

- The CORPs who participated possessed skills on net re-treatment, fever management, income generation, and use of malaria guidelines.

- The TBAs who participated had skills on early recognition of problems, advising clients, making referrals, and assisting in deliveries.

- The presence of organized groups, such as the Bungoma Community Health organization (BUCHO), formed during the BDMI. The BUCHO was formed to mobilize communities and coordinate the distribution of ITNs. The participation of the community through organized groups has been one of the innovative ways of linking the community with the health care system. There are now plans to link some of these groups with the AMREF maanisha HIV/AIDS program in order to expand their activities and interventions beyond malaria.

- Political will from key government officials at district levels also helped to sustain MIP interventions, as demonstrated through committees chaired by politicians and malaria functions (e.g., African Malaria Day) presided over by politicians.

Some conditions outside the district and the scope of the project contributed to sustaining the MIP services. At the national level, the launching of the National Malaria Strategy in April 2001 provided favorable conditions because it incorporated key interventions of the BDMI. The strategy recognized SP as the first line of treatment for malaria and recommended the provision of IPT/SP and ITNs through existing ANC services. A separate ITN policy launched in 2005 (MOH 2005) emphasizes both the biologically and economically vulnerable groups in the

\footnotetext{
${ }^{4}$ Information regarding how much support (in monetary terms) has been received from these sources was not readily available. However, it was reported that support has been in the form of training for providers and supplying drugs (SP) and ITNs.
} 
distribution of ITNs - criteria that were developed during BDMI. BDMI experiences have been used to implement and scale up ITN and IPT components of the national malaria strategy.

At the regional level, the Abuja Declaration on Roll Back Malaria in Africa (2000) was key to the sustainability of BDMI interventions. In this meeting, African leaders resolved to ensure that at least 60 percent of those most at risk of malaria (pregnant women and children under age 5) sleep under ITNs by the year 2005. For Kenya, this involved a commitment to raising the rate of ITN use from about 10 percent to 60 percent (Seltzer 2002). Kenya reduced taxes on imported, ready-made mosquito nets but retained a 20 percent tax on netting materials, as an effort to achieve this goal.

Within East Africa and the Great Lakes region, the East African Rollback Malaria Network (EARN), comprising 11 countries, has been key in setting the malaria agenda ensuring that countries meet targets and goals set at the international level. EARN members often hold routine meetings to assist countries in planning and evaluating malaria activities.

These national and regional policies and conditions, although outside the scope of BDMI, have contributed significantly to its sustainability by prioritizing MIP in their activities. For example, the Abuja declaration contributed to a significant reduction in the price of ITNs from 300 KES300 (US\$4.30) to the current price of KES50 (\$0.71).

\subsection{Malaria in pregnancy interventions beyond the project district}

The sustainability of MIP interventions beyond the project district was assessed through reviewing IPT and ITN coverage at the national level, and BDMI's influence on policy change, development of new service delivery guidelines, and drug distribution channels at the national level.

\subsubsection{Change in malaria treatment policy}

BDMI contributed to the change in government malaria treatment and drug supply policy. As members of the National Malaria Coordinating Committee, the BDMI team successfully advocated for the adoption of SP as first-line anti-malarial treatment (Seltzer 2002). Research studies done by BDMI found that chloroquine resistance was widespread, while SP was more effective in dealing with the malaria parasite.

Data collected from BDMI drug vendors showed that, once trained, vendors can give correct advice on drug dosage on SP. On the strength of these findings, and combined with evidence from shopkeeper training in the Kilifi district, BDMI lobbied the Drug Standards and Regulations Board at the $\mathrm{MOH}$ and the Pharmacy and Poisons Board for SP to be removed from the list of prescription-only drugs to become an over-the-counter drug. The original policy led to prohibitive costs to small businesses, and so this legal change was critical to the success of BDMI's training program for drug vendors and CORPs to provide SP. This change was implemented at the national level and so has improved access to SP nationwide.

Two key interventions that were developed and piloted under BDMI in relation to drug supply and ITN distribution ended up having a national relevance: the Vendor-to-Vendor (VTV) and the 
Jirani kwa Jirani (JKJ) “neighbor-to-neighbor” education strategies and distributing ITNs through community-based groups. The VTV strategy involved training wholesale drug vendors to communicate the new malaria guidelines to drug retailers and providing job aids for shopkeepers and clients (Seltzer 2002). JKJ sought to increase community demand for correct drug treatment by encouraging people to convey messages about malaria to each other. By 2003, there was evidence that JKJ was being rolled out in other districts (e.g., Kilifi and Homa Bay) through the support of MOH (Olenja, Mwanza, and Andolo 2003).

\subsubsection{Development of new service delivery and training guidelines}

BDMI influenced the development of new service delivery guidelines through supporting the revision of existing materials for use by health workers and the community using BDMI experiences and WHO recommendations. The existing handbook for clinical management and treatment of fever was revised to become the national guidelines for diagnosis, treatment, and prevention of malaria for health workers (MOH 2003).

The development of a national training curriculum for TBAs was another key impact of the BDMI. TBAs were identified as key actors in the provision of services that improve prevention and management of MIP, such as ensuring provision of SP and ITNs and making referrals for specialized care. However, it was realized that most TBAs lacked skills that enabled them to provide quality ANC, and some of their practices were unsafe (Seltzer 2002). The BDMI supported revision of the TBA training curriculum with support from $\mathrm{MOH}$, which led to the development of a new national training curriculum for TBAs.

\subsubsection{National IPT coverage}

By the end of the BDMI, IPT had evolved into a national policy that was to be implemented in all government facilities. BDMI experiences were crucial in the adoption of IPT using SP as a national policy. The malaria policy states that the government will ensure that all pregnant women living in malarial areas have access to two free SP doses, or other prophylactic regimen, which may evolve as IPT for malaria (MOH 2001). The policy put in place strategies for ensuring that IPT was delivered to all pregnant women as a means of preventing MIP. A 60 percent national target by 2006 was set.

The Kenya Demographic and Health Survey 2003 (CBS, MOH, and ORC Macro2004) reported a national coverage of 4.2 percent for women who had delivered in the last 12 months and who took 2 doses of SP as IPT. The coverage for the Western Province, which includes the pilot district, was 7 percent. About 84 percent of health facilities in Kenya offer preventive antimalarial treatment (NCAPD et al. 2005). The national scale-up of IPT was accompanied by retraining of health providers, but according to the KSPA, only 11 percent of all ANC providers had received training in IPT with SP in the preceding 12 months; the same percentage was reported for Western Province. Reaching the goal of 60 percent by 2006 seemed unlikely.

\subsubsection{National ITN coverage}

Efforts to increase provision of ITNs nationally have been strengthened by putting in place an appropriate policy framework, and concerted efforts have been made to mobilize resources for purchasing ITNs. The ITN policy, launched in 2005, addresses access and distribution, and was informed by BDMI. The malaria policy proposes that, by 2006, 60 percent of the population at 
risk will sleep under nets, and that at least 50 percent of these will be treated regularly with insecticides. However, no nationally representative figures for net usage are available, apart from periodic monitoring of net coverage and re-treatment in a few sentinel districts in the RBM campaign; these estimated net usage at 15 percent to 20 percent of households (CBS, MOH, and ORC Macro 2004).

The MOH adopted a pro-poor approach in its ITN policy following the success of BDMI in using an approach that aimed at ensuring that nets are distributed freely or at subsidized costs until the Abuja targets are achieved. Consequently, resources have been mobilized from health development partners, especially USAID, UNICEF, and DFID, as well as the Global Fund, to provide subsidized nets throughout the country. Aggressive social marketing of ITNs by PSI has considerably improved access; ITNs are currently distributed countrywide through the PSI social marketing program at a subsidized cost that is aimed at reaching the most biologically and economically vulnerable groups. Figure 3 shows the national net/ITN coverage as reported in the Kenya Demographic and Health Survey 2003 (CBS, MOH, and ORC Macro 2004) and by the $\mathrm{MOH}$, Kenya (MOH 2005). Although the coverage in 2005 was higher, it was still far below the national target of 60 percent by 2006; the proportion of ITNs re-treated within the appropriate time has nearly reached the 50 percent target set for 2006. Overall, the figures indicate that efforts have been made to scale up ITNs in line with national policy, despite insufficient funds to purchase enough nets to be distributed freely through government facilities.

Figure 3: The national net/ITN coverage for 2003 and 2005

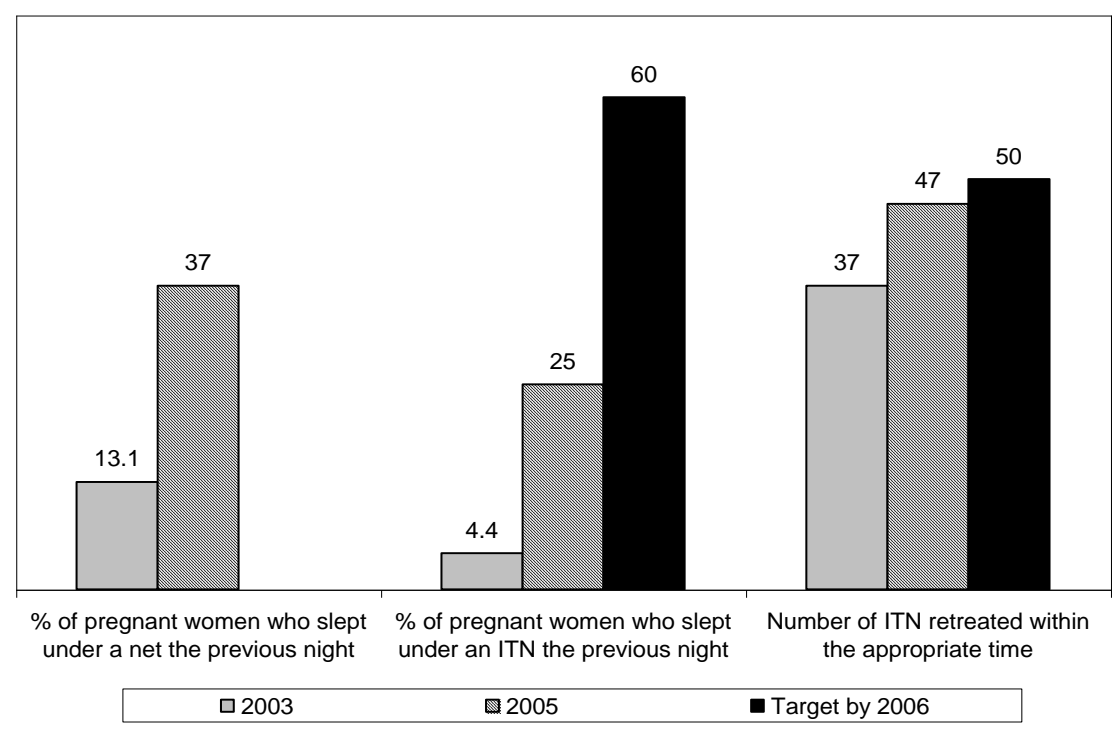




\subsection{Key factors for sustainable interventions}

\subsubsection{Integration of new services into the existing health system}

Innovative services should be able to be maintained within the existing health system. The BDMI was implemented using the existing personnel and within existing infrastructures. Interventions such as IPT and ITN are now routinely included in district and national plans, hence guaranteeing their continued delivery as standard services. IPT and ITN are specified in the national policy and strategy, which will ensure their provision "Sustainability was critical for the district health system insofar as it has to accept donor projects that can be continued/maintained within existing infrastructure. Projects that are too expensive to implement are most likely to be unsustainable. For example, research projects are too expensive in terms of skills and resources to be sustained by the district health system. Community participation is also critical for the sustainability of community health projects." (Former Bungoma DMOH). through the government health system.

\subsubsection{Development of evidence-based best practices for change in policy and practice}

The BDMI succeeded in piloting and developing evidence-based best practices for improved management and control of MIP. These practices were adopted at the policy level and have become models for replication in other districts. IPT using SP evolved into the best practice for dealing with MIP, which led to a change in treatment policy. New service delivery guidelines were developed for use in line with the new treatment policy.

Other best practices included the JKJ education strategy and VTV drug distribution strategies. The BDMI was able to demonstrate that vendors, once trained, could give correct advice on drug dosage of SP. Evidence from VTV drug distribution convinced the government to redesignate SP to make it available over the counter.

The BDMI also developed a pro-poor approach to ITN distribution, which involved the distribution of subsidized ITNs to economically and biologically vulnerable areas. This approach was adopted at the policy level and has guided the scaling-up of ITN distribution at the national level.

\subsubsection{A clear human resource development strategy}

A clear training strategy is essential. Under BDMI, training was done at the district, facility, and community levels as part of an overall human resource development strategy. The DHMT was trained in supervision, monitoring, and evaluation. Providers at the facility level (nurses, clinical officers, and public health technicians) were provided with skills such as essential obstetric care, malaria management, net re-treatment, communication skills, case management, and community mobilization.

\subsubsection{Capacity building for local groups}

Projects should strive to build local capacity and foster community participation as a means of ensuring sustainability. BDMI put a lot of emphasis on empowering local organized groups through training and awareness programs. Organized groups, such as BUCHO, were trained in various skills that would help them sustain interventions. CORPs were trained on net retreatment, fever management, income generation, and public relations, while TBAs were given 
skills on early recognition of problems, advising clients, making referrals, and assisting in deliveries.

\subsubsection{Capacity for resource mobilization}

Sustainable MIP activities should put in place mechanisms for mobilizing internal and external resources to ensure continuity. At present, the Bungoma district has been able to mobilize resources from the central government through the primary health care fund and from the corporate sector and pharmaceutical companies. External resources have been mobilized from the Global Fund, DFID, EU, USAID, and PSI. Health development partners have provided resources for MIP services to supplement district resources in order to accelerate achieving Abuja targets.

\subsubsection{Staff retention}

Sustainable MIP interventions need explicit staff retention strategies. Although BDMI had no formal strategy for staff retention, there were informal agreements between stakeholders at the provincial and national level not to transfer staff for the duration of the project. One DHMT member was seconded to the project on a full-time basis. At the district level, there were informal agreements not to transfer staff while in-charges were trained. Strategies to ensure that essential skills are retained where can be achieved, for instance, using the cascade training approach, where trained staff immediately train others either on the job or formally.

\subsubsection{Fostering public-private partnerships}

Projects should seriously consider fostering public-private partnerships that would ensure interventions are sustained beyond the project. Such a strategy prepares local private organizations involved in similar activities for the uptake of interventions through partnerships with the public health system and communities. The BDMI created links between several actors dealing in products essential for the implementation of MIP interventions. These included shopkeepers, wholesalers, net distributors, pharmaceutical companies, pharmacies, and vendors. The BDMI project coordinator summarized the project sustainability and exit strategy as follows:

"Vendors were linked directly to pharmaceutical companies, and drugs are now sold to them at subsidized prices. Groups like BUCHO were trained and linked to PSI so that they continue with ITN distribution. Training was given to BUCHO and vendors as part of our exit strategy."

These links were essential for the supply of SP and ITN and the continued provision of the MIP interventions after BDMI exited. 


\subsection{FINDINGS (MALAWI)}

\subsection{Continuation of MIP interventions in the Blantyre district}

The BIMI has been sustained in terms of health services and improved health of pregnant women, as evidenced by levels of IPT and ITN coverage, household health behaviors (sleeping under a bed net), and improved knowledge of MIP, among mothers.

A comparison of SP and ITN use between 2004, when the BIMI project was still in operation, and 2006, when the project ended showed that health services under BIMI had been sustained. ANC card reviews and interviews with women revealed sustained health behaviors. Nearly 80 percent of the ANC cards indicated that SP was given to clients at least once. The results compare well with those reported by women themselves (see Table 1). The required number of $\mathrm{SP}$ doses is at least two times during the whole pregnancy.

Table 1: Proportion of pregnant women who received SP

\begin{tabular}{|c|c|c|}
\hline & $\begin{array}{c}\text { Record of SP on ANC card } \\
\text { Recorded times of taking SP }\end{array}$ & $\begin{array}{c}\text { Proportion of women who } \\
\text { reported receiving SP } \\
\text { Cumulative percentage } \\
\mathbf{N}=\mathbf{3 2 8}\end{array}$ \\
\hline Once & $\begin{array}{c}\text { Cumulative Percentage } \\
\mathbf{N}=\mathbf{3 2 8}\end{array}$ & 81.5 \\
Twice & 80.4 & 62.9 \\
Three times & 65.8 & 18.6 \\
Did not take & 14.6 & 18.6 \\
\hline
\end{tabular}

Respondents demonstrated a high knowledge of why ITNs and SP should be used by pregnant women. When asked for reasons why they had taken SP, 88 percent correctly answered that it was for preventing malaria. Close to 70 percent of the women slept under an ITN during the previous pregnancy; the reasons given for doing so were to prevent malaria $(78.8 \%)$ and to prevent mosquito bites $(32.4 \%)$.

The proportion of health facilities providing SP under Directly Observed Treatment (DOT) was 85 percent, and the proportion of facilities that provided ITNs routinely to ANC clients was 81 percent. These proportions indicate a high level of MIP services provided. Although no baseline figures exist, this level of achievement has obviously taken a relatively short time - the program was established about three years prior to this assessment.

More than half the providers said they thought the availability of SP (53.8\%) and ITNs (52.2\%) was about the same as in the previous year (i.e., when BIMI was operational). The rest thought it was fluctuating (30\% to $42 \%$ ) or even falling ( $4 \%$ to $9 \%$ ). This is a signal that there were some constraints being experienced regarding these commodities. The possible explanation is the SP shortages at the Central Medical Stores (CMS). The expected importation of ITNs did not take place, and efforts to manufacture the nets locally in Malawi or to contract a factory in Tanzania to manufacture for Malawi were unsuccessful. This situation also caused a relative ITN shortage. 


\subsection{MIP activities beyond the Blantyre district}

MIP interventions have now been adopted as national programs. These interventions have therefore continued not just over time, but they cover all 28 districts. The key indicators of the MIP interventions are the first and second doses of SP and the proportion of pregnant women sleeping under ITNs. The ANC attendance rate in Malawi was already high, beyond 90 percent, and so was the first SP dose. The second dose rose from the baseline of 37 percent in 2000 to 69 percent in 2004 by a national survey (MOH 2004c). The proportion of women sleeping under ITNs was not specifically captured in 2000. However, surveys show that in 2004, 43 percent of households had a net; in 2003, this proportion rose to 63 percent. This survey suggests that the proportion of pregnant women sleeping under ITNs was 32 percent.

A national coverage and utilization survey done in 2003 (MOH 2004a) showed that 1.8 million nets had been distributed, and 69 percent of the nets were treated within 1 year. Although 43 percent of households were found to have a net, this number has now increased to more than 60 percent. Despite this achievement, cost was identified to be the biggest deterrent to the acquisition of ITNs. The survey also found that 87 percent of household heads had a good knowledge of malaria, but only 50 percent of the vulnerable population knew about malaria.

A survey in 2000 found that the BIMI IPT approach produced remarkable results. A total of 98 percent of pregnant women attended ANC at least once, and 54 percent attended ANC three times. A total of 37 percent received 2 doses of SP, and 95 percent of Health Centers (HCs) were found to have a good stock of SP. The combined ITN and IPT strategy has reduced placental malaria from 32 percent to 23 percent, reduced LBW from 23 percent to 10 percent, and reduced malarial anemia by 35 percent (National Statistical Office and ORC Macro 2000).

Table 2 shows progress in achieving MIP indicators.

Table 2: Progress of MIP indicators over the past five years

\begin{tabular}{|l|c|c|c|c|c|}
\hline MIP Indicators & $\mathbf{2 0 0 0}$ & $\mathbf{2 0 0 2}$ & $\mathbf{2 0 0 3}$ & $\mathbf{2 0 0 4}$ & $\mathbf{2 0 0 6}$ \\
\hline $\begin{array}{l}\text { SP Dose 1 (\%) } \\
\mathrm{n}=32,000(2004) \\
\mathrm{n}=26,886(2006)\end{array}$ & 59.9 & NA & NA & 93 & NA \\
\hline $\begin{array}{l}\text { SP Dose 2 (\%) } \\
\mathrm{n}=24,275(2004) \\
\mathrm{n}=21,148(2006)\end{array}$ & 27 & NA & 69 & 60 & NA \\
\hline ITN Coverage (\%) & 13 & NA & NA & 43 & NA \\
\hline ITN use by pregnant women & NA & NA & NA & 31.5 & 67.5 \\
\hline
\end{tabular}

Notes: (1) NA means "data not available”; (2) SP dose 2 for 2005 and 2006 are extrapolations from the BIMI study; (3) The rest of the figures are from national surveys, namely the Malawi Demographic and Health Survey 2000 (National Statistical Office and ORC Macro 2000) and the National Malaria Survey 2004 (MOH 2004c). 


\subsection{Capacity and viability of the district health system to sustain services}

The BIMI was able to operate successfully because of an enabling policy environment and organizational framework. BIMI was designed to be embedded into the national health system and to operate through the government organizational structure. The key elements of the structure are as follows.

MOH Leadership: The capacity for malaria control and management encompasses national district and community organizations, their links, and ability to perform. The MOH provides political and technical leadership, departments, and other units. The political and technical leadership has a thorough understanding of malaria, has put malaria control at the center of $\mathrm{MOH}$ activities, and has a measure of the entire health sector performance. The focus on malaria started in 1984 but has not changed with different personalities or governments. In fact, the focus has only been more intense, with better evidence and evidence-based interventions becoming more available.

The MOH leadership had an early start and persistent focus on malaria as a national priority. It has committed itself to evidence-based interventions, using what works. Using what works, it has sought to convince and rally development partners for financial and technical support. The $\mathrm{MOH}$ leadership has developed a strategic partnership with donors and partners. This entails not only using interventions that work but using those that are also acceptable to the partners.

For example, DDT, notwithstanding its environmental hazards, has proved in the past to be the cheapest and most effective strategy against malaria. DDT has been endorsed by the Common Market of East and Southern Africa (COMESA) as a regional malaria strategy. The $\mathrm{MOH}$ is reviewing the use of DDT with its partners and stakeholders. In addition, the bold decision by the government to subsidize ITNs underscores the strong political will and the support of the political leadership for malaria control.

МOH Organization: $\mathrm{MOH}$ departments and units have linked up strongly on malaria. They enhance each other's work. Malaria control comes under the Department for Preventive Health Services. This department is guided by the overall health policy, whose goal is providing an Essential Health Package (EHP) free of charge to reduce the burden of disease. Malaria control is an integral part of the EHP. ITN and SP are key malaria control interventions, which are implemented jointly by Reproductive Health Units (RHUs) and the National Malaria Control Program. The Safe Motherhood Program of Malawi was instrumental, through an operational study, in identifying the factors of the low second dosage of SP, and in preparing tailored responses to address these factors.

The Pharmacy, Medicines and Poisons Board (PMPB) is a regulatory body that plays a critical role in ensuring that only good quality drugs are imported into Malawi and are used by patients. The board plays a key role in the supply and quality of SP, which is why BIMI supported PMPB.

BIMI was represented on the Steering Committee (SC) of the MOH. There was a Task Force of the SC on MIP, which met quarterly. BIMI was a key member of this Task Force. BIMI's MIP program ran from 1998 to 2002. From 2002 to 2006, BIMI activities went beyond the Blantyre 
district and included national-level support. The national project was renamed the CDC-Malaria Malawi Project. BIMI directed the project and operated at the heart of the MOH.

District-Level Organization: The district-level organization is currently not fully decentralized. District Health Officers (DHOs), for example, are agents of the GOM. Therefore, there is high likelihood of compliance with national policies at the district level. BIMI took advantage of this arrangement to work at the district level as well as at the national level to ensure their activities would be implemented effectively. Greater decentralization, with more powers to the district will be introduced soon. Measures will need to be put in place to ensure that national priorities, such as malaria control, do not get lost at the district level.

Communities are organized under traditional leaders or chiefs, for whom people have a great deal of allegiance and respect. It is therefore highly feasible to organize developmental activities through the chiefs. In addition, the new cadre of Health Surveillance Assistants (HSAs), who live in communities, links very well with chiefs and other community leaders, such as religious, opinion, or institutional leaders. BIMI was aware of these structural arrangements and took advantage of them to plan and implement the project.

Community-Level Organizations: There is also recognition of the role TBAs now play in providing ITNs and SP. NGOs such as WVI did not lose trust in or touch with TBAs, even when $\mathrm{MOH}$ and other partners did. The reason why WVI, for example, continued to have faith in TBAs is that TBAs have been and will always be in communities. It is better to work through them because they are trusted by the community.

Traditional local leaders (chiefs) and councilors are involved in development activities. Their involvement is often increased during mass treatment of malaria with ITNs. They command a lot of respect, people listen to them, and people obey them. HSAs will be stationed in each village as a link between the formal health system and the community.

Human Resource Situation: Almost 70 percent of the health facilities surveyed had at least 2 MIP service providers, and 65 percent of these providers had received at least some training in MIP. There was, therefore, a reasonable availability of trained staff for MIP services. No comparable study had been done to assess whether staff availability was improving.

However, it has to be noted that BIMI was implemented in the context of a serious human crisis that could potentially prevent its successes from being sustained or scaled up. At the initiation of the BIMI project, this problem was not felt because staff numbers were sufficient, and they were motivated. However, at the national level, although staffing through the Human Resource Department (HRD) is being addressed, it remains a critical problem. How it is managed will determine the sustainability of MIP services introduced by BIMI. The GOM and other partners are handling the human resource issue.

The human resource crisis includes problems with staff retention and the staff leaving public service at a higher rate than those being trained or joining the service. Most of the critical staff, the nurses, are going abroad, especially to the UK. Doctors are leaving public service for private practice. This follows the liberalization of the health care market. Most doctors do not work in the public sector. Of 18 doctors who graduated in 2004, only 2 have remained in the $\mathrm{MOH}$, the 
rest (16) have gone into private practice or left the country or joined the NGO sector. Nurses are now in high demand by NGOs and are highly paid. So they are leaving the public sector at an alarming rate, either to go abroad or join the NGO sector.

An HR Strategic Plan 2003-2006 was developed that supports CHAM to double its intake in training health personnel. The idea is that although some staff will leave, a good number will remain in the country. DFID is financing a staff retention program, started in 2005, where staff salary is increased by 52 percent. However, CHAM staff are still better paid because CHAM has Income Generating Activities (IGAs) from which it raises additional revenue. Therefore, in spite of the MOH staff salary increase of 52 percent, the staff are still leaving to join CHAM because the total pay is higher.

A second strategy for staff retention is providing non-monetary incentives (water, electricity, and housing). This approach is being supported by the GOM, the Norwegian Church Aid, and DFID. GTZ also provides hardship allowance as a third strategy. However, the project implementing this strategy ended in January 2006. A fourth strategy is a tripartite partnership between CHAM, $\mathrm{MOH}$, and training schools, through a Memorandum of Understanding (MOU) to pay hardship allowance to Nursing School Tutors. Overall, the government's strategy is to increase salary on a yearly basis to match economic realities and to move toward prevailing market rates. Vertical programs and projects already pay salary increases, which are substantial.

HSAs form the bulk of health work force. They are located in remote rural health facilities and interact with communities. They are paid a salary but are not yet included in the salary top-up program. The HSAs are responsible for the campaign on measles, immunization, environmental, and health. They are usually recruited after acquiring a Malawi School Examination Certificate and are trained for six weeks. For the country's population of 12.6 million, 12,600 HSAs are required, but now there are only 4,566 HSAs. There is a program to train another 8,000 HSAs.

With a decentralization policy being introduced now, HSAs will become the responsibility of district authorities. District authorities will be expected to recruit and pay the HSAs. However, from 2015, it is envisioned that HSAs will no longer be required because a critical mass of qualified staff will be available.

Procurement and Logistics: BIMI partnered with PSI to warehouse and distribute ITNs. UNICEF procured ITNs for BIMI. SP was procured and distributed by the CMS. BIMI also supported PMPB for quality assurance, especially in testing for the quality of SP and insecticides. The Department of Technical Support looks after physical property, equipment, and physiotherapy. It has four sections, each headed by a deputy director: pharmaceuticals, diagnostics, physical assets, and physiotherapy.

BIMI and Central Medical Store: The CMS is a semiautonomous body for storing and distributing drugs and supplies. The CMS is being restructured in such a way that drugs will be bought by districts at the CMS. This approach is in line with the decentralization policy. The CMS is being capitalized and supported with technical assistance through a Sector Wide Approach (SWAp). DFID and SWAp funds also are being used to support physical infrastructure development of the CMS. Therefore, BIMI relied on other partners to strengthen 
CMS, an essential public institution for the storage and distribution of pharmaceuticals, including SP and ITNs.

There had been shortage of SP at one time because of procurement problems, which included delayed emergency procurement, slow funds coming through SWAP, and a cumbersome tender and procurement system. Therefore, the buying and stocking of SP and other drugs should be implemented well in advance of any anticipated shortage. ITNs were not being ordered through the MOH's CMS but through PSI. Initially, it had been planned that PSI would distribute 1 million ITNs per year. The ITN community revolving fund also made a modest contribution to use of ITNs by the community.

BIMI's Partnership: Malawi has a good number of donors and other development partners. There is remarkable cooperation among these partners on malaria as a national priority. This cooperation has been demonstrated with increased funding for malaria activities. There is a general agreement among donors to fund strategies that work. The donor partners have also shown remarkable trust of the evidence on what works from the government and other partners. Above all, development partners are usually participants of research, and policy and guideline development.

The control of malaria in Malawi, like in other countries in Africa, depends on the capacity of the health systems as well as on the level of the economy. It also depends on the partnership, the nature of the relationship with partners, and the levels of funding from donor partners. Malawi has managed to build a good partnership around its technical policy and strategies on malaria, and this partnership is based on trust, evidence, and goodwill.

BIMI fitted well in this arrangement, where the project partnered with government as well as private-sector organizations. The continued trend of this partnership will ensure a long-term action on malaria, and its sustained control, leading to its eventual eradication.

Another important aspect of viability of a program is the extent to which funding will be mobilized in a sustainable way. Within the malaria control section, unprecedented levels of funding have been mobilized. The funding levels can be maintained or increased because of the good partnership, trust, and goodwill that prevail. However, the government needs to project how its own internal resources should, over the next 10 to 20 years, replace, in phases, some of the aid resources that will certainly be reduced in the future. The GOM has embarked on an economic growth policy to strengthen the economy, which should be able to shoulder an increasing amount of social services using internally generated resources.

BIMI and PSI: PSI's involvement in BIMI projects started with the MOH identifying ITNs as a major/strategic intervention for malaria control. The MOH identified PSI as a body that could store and distribute ITNs effectively. This collaborative effort received funding from the CDC, UNICEF, the BIMI, and the MOH. The success of a high ITN coverage in Malawi can be attributed to: (1) consensus on the ITN strategy; (2) clear guidelines, specifying responsibilities and roles; (3) adopting a partnership approach, not a project approach; (4) a strong leadership from the $\mathrm{MOH}$; and (5) the conviction of donor partners. 
PSI's strengths and roles were (a) clearing (after procurement by UNICEF), (b) packaging and re-impregnation with insecticide (where this was found inadequate), (c) warehousing, (d) recording, and (e) salesmanship and distribution to selling points. The delivery to the selling points is done by mobile sales teams. The products are physically counted, reconciled with funds, and banked. Nurses were trained to sell to pregnant women and women who had fewer than five children. Some security problems, such as car hijacking and thefts, were anticipated and guarded against.

Nurses were given an incentive of 10 kwacha per net. Therefore, a 40 kwacha ITN was sold at $50 \mathrm{kwach}$. Initially, there were problems with accountability, but these were overcome.

Demand creation was done through the radio, posters, and during mass treatment exercises just before peak mosquito season. The message changed over time, starting with "a net is good for preventing malaria," to "you have to sleep under the bed net every day to prevent malaria." The change of messages was driven by the problems identified by a survey: (1) initially, to raise awareness, (2) to use an ITN all the time, (3) to retreat nets every year, and (4) to target women and under-five children as a priority.

PSI had the confidence of the MOH and donors from its previous work on marketing condoms. The nationwide scale is what sets Malawi apart from other countries where ITN programs are usually on small scale. The government has played an enabling role. There has been open and clear communication with all partners, both formal and informal. All messages to the public and stakeholders are consistent. Monthly sales reports are shared with all partners. The key partners in the ITN distribution are the DFID, the MOH, PSI, UNICEF, JICA, SWAP, the Global Fund, and USAID.

BIMI's influence on the Malaria Policy: The BIMI project helped control malaria, and they managed the project by providing financial support, developing policies, and helping to implement ITN and IPT policies. The project was instrumental in shaping policies and practices through operational research, which was problem-based. Examples include setting the SP dosage schedule and the work on long-lasting nets.

The GOM currently uses four key strategies in malaria management nationwide: (1) ITNs, (2) IPT, (3) early diagnosis and treatment, and (4) nutritional supplements. The MOH and partners designed the ITN program by incorporating experiences from the BIMI/CDC, NGOs, and PSI. Partners were identified to distribute ITNs; guidelines of ITNs were developed; and standards were set for procurement, logistics, quality, pricing, cost recovery, and the use of the revenue collected. Finally, a monitoring and evaluation system was designed and established.

The ITN distribution was planned to be large-scale, based on the strategic partnership of the public sector, commercial enterprises, and NGOs. It included community capacity building, demand creation, and strengthening of the health system.

MIP interventions are part of the EHP, which the GOM has defined and is determined to provide to the whole population. The ideal funding for the EHP is estimated to be US\$28 per capita, but the $\mathrm{MOH}$ planners acknowledge that a reasonable funding of $\$ 17.50$ would be adequate. However, $\$ 12$ is currently available, of which only $\$ 4$ is from the GOM, $\$ 3$ from out of pocket, and $\$ 5$ from donors. More and long-term funding is being sought through strategic partnership 
with donors, in which the GOM and donors agree on a common strategy. Donors are encouraged to support the country more if such an agreed strategy produces results.

BIMI and the SWAp: The SWAp is the agreed vehicle for the delivery of EHP (MOH 2004b). BIMI supported and participated in its conception and design. This is intended to enable MIP interventions to cover the whole country. The MIP program is a combined strategy of reproductive health, malaria control, and HIV/AIDS management, which are key elements of EHP. Malaria control by its very nature involves many stakeholders. They include donors, pharmaceutical companies, businessmen, and policy makers. There is always a tendency for each actor or stakeholder to take a narrow view and act narrowly and in parallel or even against other actors. This not only leads to lack of coordination and failure to harness available efforts and resources, but could derail the health sector from attaining the goal of eliminating malaria in the country. SWAp provides a new opportunity in a situation where there are numerous actors and stakeholders in the health sector. SWAp helps to bring all actors and stakeholders together to focus on the same goal, using the same strategies, and in a complementary manner. Malawi's SWAp is therefore timely, in the right direction, and a positive factor in sustaining MIP interventions.

\subsection{Best Practices from BIMI}

\section{BIMI designed based on research and innovation}

A baseline study was done at the start of BIMI, which led, in 1998, to starting an ITN distribution program, with HSAs as the key ITN sellers. It did not take long to find out that accountability of funds by HSAs was a huge problem. In 1999, there was change from HSAs to nurses as the primary sellers of ITNs. This change occurred because the target of the ITNs changed from being the community as a whole to the priority groups of children under five and pregnant women. These groups are handled and often pass through the hands of nurses. Initially in 1999, the ITN program was in one district, and then in 2002 it expanded to three districts.

In 2003, a decision was made to expand the ITN program countrywide. This decision was based on a survey, which showed that while the first dose of SP in pregnancy was given to 92 percent of the women, the second dose was much lower, given to only 37 percent. The survey led to a tailored feedback, in which specific problems in management were addressed. The key problems were: (1) pregnant women not complying with SP prescription, unwilling, and refusing to take the drugs; (2) nurses were confused about when to give the first and second doses; and 3) nurses being unsure about the gestational age of pregnancy.

Therefore, BIMI established DOT and public education to address the lack of compliance and mothers' unwillingness to take SP. The BIMI staff made a wheel to calculate gestational age as a basis for determining when to give the first and second SP doses. A follow-up survey in 2003 showed that the second SP dose coverage increased from 37 percent to 69 percent.

Urban and Rural Integrated Management of Childhood Illnesses (IMCI) models were developed and implemented by school teachers. It was observed that DOT required water and cups, which many health facilities did not have. A DHO revolving fund with 500 seed nets was started in the 
Blantyre district. Each net was sold at $\$ 0.50$ to staff and communities. These were green conical nets. The blue conical nets were sold in bins the open market at $\$ 3$.

A number of studies have been done by BIMI and CDC-MMP, in collaboration with NMCP, and include: (1) SP cutenous reactions, (2) anemia as an indicator of malaria problems, (3) assessment of demand against increasing subsidy, (4) using EPI and ANC rewards to reach the very poor in rural and urban areas, (5) long-lasting ITNs, and (6) a Drug Change Plan. These studies have informed policies and practice in malaria control.

Although the project had officially ended, its activities continued and became routine, and have now expanded countrywide. The project implemented MIP interventions with a problem-solving approach. The project ensured predictable and constant supply of SP and ITNs. The project also worked on the quality of drugs through testing for the dissolution of SP. The project helped to scale up IPT practices and to make them routine nationally. This was through the projects' financial support in the development and implementation of national policy and guidelines, and in monitoring and evaluation.

The BIMI introduced ITNs in HCs, hospitals, and maternity wards to demonstrate the universal use of the nets for pregnant mothers in all settings, and also to remind both staff and their clients about the need for pregnant women to sleep under ITNs. The CDC and the $\mathrm{MOH}$ are currently piloting an innovative scheme to reach the very poor who still have an economic barrier to ITNs. This scheme follow a study done under the BIMI in which it was found that access to and the use of bed nets increased proportionally with household income. In the "access promotion" scheme, ITNs are provided free of charge to children who complete their vaccination schedule. Also, pregnant women who fully complete their ANC schedule are given a free ITN.

The BIMI project, throughout Malawi, provides remarkable best practices in the management of MIP specifically and health services in general. These best practices can be categorized as (a) general, (b) IPT-specific, and (c) ITN-specific.

\section{General Best Practices}

Problem-oriented approach: The BIMI project and the Malawi health sector in general have demonstrated that problem-oriented, evidence-based solutions work well. The specific interventions cataloged in the following paragraphs demonstrate this observation.

Strategic partnership: The GOM needs the financial and technical support of a donor partnership, and this is based on a strategic partnership. This means the partnership is long-term, based on mutually agreed strategies, and critically, on the basis that the strategies work and produce the desired results. The partnership on ITN, for example, has a long-term (20- to 30year) horizon, with the goal of eliminating malaria as a public health goal. On its own, the GOM would probably not achieve this goal within the targeted time frame.

Tailored response: Often, general responses are given by the GOM to different individuals or communities when a common health problem occurs. The approach in Malawi is innovative because the responses given to different health personnel and clients were tailored to their local context. This was demonstrated, for example, in conveying guidelines and policy to HC staff and in educating mothers on IPT. It was also demonstrated in redesigning patient flow in each 
health facility to enable DOT to be given. The Table 3 summarizes the GOM's tailored responses to increase the low percentage of women receiving a second dose of SP.

Table 3: The GOM's tailored responses to address problems with a second dose of SP

\begin{tabular}{|l|l|}
\hline $\begin{array}{l}\text { Problems with SECOND Dose } \\
\text { of SP }\end{array}$ & \multicolumn{1}{c|}{ Tailored Responses } \\
\hline $\begin{array}{l}\text { Noncompliance with SP } \\
\text { dosage }\end{array}$ & $\begin{array}{l}\text { - Used DOT } \\
\text { - Reorganized patient flow }\end{array}$ \\
\hline $\begin{array}{l}\text { Confusion over timing for the } \\
\text { second dose of SP }\end{array}$ & $\begin{array}{l}\text { - Used a gestational wheel to estimate time for second dose } \\
\text { of SP }\end{array}$ \\
\hline $\begin{array}{l}\text { - Used quickening to estimate time for first dose of SP } \\
\text { - Gave first and second doses of SP one month apart } \\
\text { taking SP tablets }\end{array}$ & - Simplified guidelines and disseminated them widely
\end{tabular}

Conducive economic and policy environment: The GOM has demonstrated harmony between health and economic policies. To enable better access to both ITN and IPT, ITN was subsidized and tariffs were removed. This harmony is necessary and reinforces both health and economic policy goals. Healthier populations are more productive in the long run than unhealthy ones.

Simplification of policy and guidelines: A common problem in implementing health programs is the failure to communicate the policy and guidelines. These may be difficult to understand or not made available for end-users. In Malawi, a deliberate effort was made to simplify and shorten key elements of policies and guidelines on IPT and ITN and make them widely available to all end-users. The effort paid off.

Revolving funds: Although not a new idea, the insistence on revolving funds for both ITNs and drugs led to better mobilization of communities, better ownership of the program, and a better and appreciation of these two items in malaria control. On its own, it would not finance the items, but the other benefits of revolving funds contributed significantly in the success of the MIP program.

\section{IPT-Specific Best Practices}

Enhancing compliance in taking SP: It was observed that many mothers did not take their SP. It was therefore decided that they would take their SP tablets at the health facility, requiring them to be observed under the DOT. Therefore, the patient flow in the health facility had to be reorganized so that a mother would be observed by a responsible staff member taking her SP dose before leaving the health facility. DOT further required cups and a supply of safe water at the health facility. All these were discovered through a step-by-step, problem-oriented approach, which greatly enhanced SP uptake.

Estimation of gestation age: At first, it was difficult for the staff to estimate the gestation age of mothers. When this was observed, the solution was to find an event in the gestation period that a mother would be able to remember. This was the first quickening or feeling of fetal movements. Once quickening occurred, it was determined to be the appropriate time to give the 
first dose of SP. A gestational-wheel device was made to estimate the date for the second and third SP doses.

Timing of the doses of SP: The staff were unsure when to give the second dose. It was determined that, as a policy, the second dose would be given one month after the first dose.

Addressing misconceptions: A number of misconceptions arose about SP. For example, it was believed that SP could not be taken on an empty stomach, or it would cause grievous harm. This and other misconceptions were gradually addressed through targeted Information, Education and Communication (IEC) and are decreasing now.

\section{ITN-Specific Best Practices}

Multiple Channel Distribution: The design of the ITN distribution was innovative. It targets 3 groups of people: the under-fives and pregnant women, the poor, and the better-off. The channels used were ANCs, community subsidies, and shops, respectively. This design was based on studies and observations on income, access to ITNs, and the attendance rate of ANCs.

Incentives to Sellers: It was found critical to give incentives to the sellers of ITNs (i.e., nurses at the health facilities and HSAs in the communities). A small price margin was left for the sellers to encourage them to do the selling.

Mass Treatment of ITNs: All ITNs were treated on the same day throughout the country through a highly publicized and high-profile function. This had two dramatic effects: (1) ensured that a good proportion of ITNs were re-impregnated with the insecticides and (2) raised awareness about the problem of malaria and ITNs as a major strategy.

Demonstration of ITNs: All health facility wards had ITNs to demonstrate to patients and staff how important it was for everybody to sleep under a mosquito net to prevent malaria.

Rewarding ANC and Immunization: Mothers who completed ANC attendances and children who finished their immunization schedules were rewarded with ITNs. This was to encourage good health-seeking behavior and to emphasize the importance of ITNs to the two groups in the prevention of malaria.

Private Sector Distribution: Where there is an effective private organization, it can handle the procurement storage and distribution. These functions are often carried out by the public sector in most countries, which can be bogged down. The PSI in Malawi has carried out of some of these functions effectively and has contributed hugely to the success of the ITN program in Malawi. 


\subsection{Discussion}

Continuation of MIP Services: The BIMI project was conceived to be implemented through existing structures, and it became embedded into and part of the national health system. Its activities started in one district, expanded to all districts, and continued after BIMI officially ended. Mothers continued to demonstrate a high level of knowledge about IPT and ITNs in preventing malaria. SP and ITNs continued to be easily available to the majority of the target groups (i.e., children under five and mothers) through a program of subsidy, aggressive promotion, and countrywide distribution.

Best practices: The problem-oriented approach was the main strategy for the success of BIMI. Partnership with donors, based on mutually accepted and evidence-based strategies, was another best practice. The use of tailored responses, focusing on communities, individuals, and circumstances was found to be extremely effective. The subsidy of ITNs was found a necessary supportive economic policy. The simplification and dissemination of malaria policy and guidelines that were easy use by end-users were found to be innovative and useful. Revolving funds were used as a strategy for community mobilization and to gain community ownership, rather than just to raise money.

IPT-specific best practices included DOT, where patient flow was reorganized for this to happen. A gestational-wheel device, and the use of quickening in pregnancy to estimate gestational age, were innovations that removed the confusion about the timing of the first SP dosage. ITN best practices included multiple-channel distribution of ITNs and using the private sector and public sector outlets. This would not have worked without giving incentives to the sellers of ITNs. Conducting a free mass net re-treatment campaign throughout the country and making it a greatly publicized and high-profile function (launched by the President) was found to be effective. The practice of putting ITNs on health facility beds to prevent malaria in health facilities was a good demonstration to health staff and patients alike on the importance of ITNs. Rewarding children and mothers who complete their immunization and ANC schedules, respectively, with ITNs was another strategy to improve the use of the ITNs by the target groups.

Potential for Sustainability: The working definition of sustainability contains two key components: integration of strategies and their nationwide application. However, other elements of sustainability included capacity building, a strategic partnership under SWAP, economic growth, integration of services and programs, and long-term partnerships, as opposed short-term projects, where continuation is uncertain.

There is multiparty democracy, which is seen by the population and international community as credible. There has been peaceful transition from one government and leader to another. It looks likely that this peaceful democracy will continue. This atmosphere makes it easy and sustainable for partnerships to work and for long-term programs, such as malaria eradication, to be achieved.

There is a general recognition and appreciation of the remarkable political will in Malawi to control and eliminate malaria in the country. The GOM has accepted that large investment on malaria control is necessary. That is why its malaria budget has gone up, and it has subsidized 
ITNs and anti-malarial drugs. In addition, the GOM is financing the salary and drugs of CHAM (NGO) health services.

The potential for sustaining MIP interventions is enhanced by positive factors that already exist. A stable and peaceful multiparty democracy, which has firmly take root, and which will ensure no interruption of long-term programs, such as ITNs and IPT, is essential for sustaining MIP interventions. Using SWAP to coordinate all actors and stakeholders to focus on the same goal using agreed and proven strategies is critical for the MIP program. Above all, the culture of using evidence and innovation in making policy and solving problems is key to the success of MIP program.

The vision of Malawi's policy makers to partner with donors for the next 20 to 30 years on mutually agreed policies until malaria is eliminated is particularly aimed at eliminating malaria in the not-too-distant future. Maintaining public-private partnership in a way that allows the private sector to do what it can do best, such as ITN distribution and social marketing, paid off. The following factors were instrumental in the success of MIP program in Malawi: (1) the ease with which communities are mobilized using traditional leaders; (2) the program to retain staff in government health services; and (3) the formalization of HSAs, previously volunteers, as salaried health staff. The totality of these strategies and approaches provides a potential mechanism for sustaining the MIP program in the future.

The potential for a national scale-up: The continuation and scaling-up of MIP interventions have been ensured by the following factors: (a) integration under SWAP as an agreed national health system (MOH 2004b); (b) strategic partnerships with donors on a long-term basis on mutually agreed interventions and strategies; (c) public-private partnership in ITN procurement, warehousing, and distribution; (d) interventions and strategies that produce appreciable results; and (e) the persistent and multiple-pronged approach.

Additional factors for future sustainability of MIP interventions are likely to be economic growth, which will increase household incomes and enable them acquire the SP and ITNs on their own, and ensuring adequate health staff, including HSAs, and retaining them.

The potential for sustaining MIP activities from the BIMI and other programs in Malawi will depend on a number of positive factors that are already in place: (1) the existing social capital and stability, (2) a democratic political dispensation in Malawi, (3) the implementation of SWAP, (4) the reversal of the HR crisis in Malawi, (5) the continued use of research in finding solutions to problems, (6) strategic partnerships, and (7) increased, internally generated financing of the programs. 


\subsection{LESSONS LEARNED AND CONCLUSIONS FROM KENYA}

- The BDMI succeeded in integrating the new services within the existing district health system, thereby eventually enabling them to be included in the district work plans. Successful introduction of the MIP strategies required adequate funding, and BDMI was sufficiently well funded to enable the project to systematically pilot innovative strategies of drug and ITN distribution, which would not have been possible within a limited budget. Adequate funding and time enabled BDMI to pilot and evaluate the strategies sufficiently well so that they became documented "AMREF's role was overall coordination and program
management and closely worked with DHMT in training and
supervision. MEASURE was contracted for documentation
purposes. QAP did problem solving. CDC provided technical input
to BDMI and conducted operational research related to MIP. The
DHMT had the main role in the project as implementers, suppliers
of staff, supervision and facilitation. The community identified
organized groups, TBAs, herbalists and did follow-up of activities.
They were also mobilizers for services offered." (Program
Manager, BDMI) best practices, which were later adopted into national policy.

- Each actor had a clearly defined role, which enhanced coordination between partners and implementation of activities. Such arrangements facilitated smooth running of the project and ensured that activities were not duplicated. Clear roles defined the boundaries within which partners operated, thereby eliminating the potential for friction, and ensured that partner strengths were optimally utilized.

- Although BDMI comprised several partners, the Bungoma DHMT and AMREF provided strong leadership in ensuring that all partners worked as a team. The BDMI did not, however, address the issue of data ownership among local and external partners, and this should be taken into consideration in the future to enhance utilization of data from research findings.

- A clear human resource development strategy was critical. Staff lacked the necessary skills and required training to be able to offer the new services. Sufficient and planned investment in capacity development is therefore vital when introducing new interventions.

- The BDMI experience highlights the importance of community involvement and participation in implementing MIP strategies. BDMI made concerted efforts to involve the community and to elicit their participation through elaborate social mobilization and capability building of different community groups, including CORPS, TBAs, and organized groups such as BUCHO. Given that the clients of MIP services come from the community, their involvement and participation were critical.

- A country considering introducing new MIP strategies should include a strong research component, as was done under the BDMI project. Such research generates empirical evidence, which can be used to convince policy makers and other stakeholders to refine existing policies and program guidelines or formulate new ones. BDMI's innovative 
strategies were supported by research-based evidence, which made the arguments to policy makers and health development partners convincing.

In conclusion, BDMI is in many respects a success story that will continue to inspire new MIP interventions. It was well planned, piloted, successfully implemented, and it has been sustained. Although the implementation strategy was costly, it is replicable in many respects. It is recommended that USAID/EA should promote MIP interventions and projects that draw on BDMI's experiences, including:

- Clearly defined roles for different partners.

- Integration of new services into the existing health system.

- Use of research to develop evidence-based best practices to guide policy change and practice.

- Development of locally appropriate innovative interventions that can be used in the community, such as JKJ and VTV.

- Strong leadership and coordination.

- A clear human development strategy.

- Active beneficiary involvement and participation.

- Capacity building for local groups.

- Capacity development at district and national levels for resource mobilization.

- Staff retention strategies.

- Fostering public-private partnerships.

BDMI's sustainability within and beyond the district can be attributed to these factors, which address both the demand and supply side of health service delivery. On the demand side, systems were put in place to ensure continuity in promoting relevant health-seeking behaviours at the community level, as well as capacity building of local groups to continue to create demand for services. On the supply side, for instance, the integration of new services into the existing health system and the production of evidence-based best practices using research, which influenced change in policy and practice, have ensured that the interventions have been adapted within the government system, thereby enhancing sustainability. 


\subsection{LESSONS LEARNED AND CONCLUSIONS FROM MALAWI}

A number of lessons can be drawn from the Malawi experience. The lessons are categorized as those from (a) the GOM, (b) development donor partners, (c) BIMI as a project, and (d) on sustainability.

\section{a) Lessons from the Government of Malawi}

- Persistent focus on national problem: There was an early and persistent focus by the GOM on malaria as a national problem and they began to systematically look for solutions. This awareness sets Malawi apart from other countries in sub-Saharan Africa, which typically identify malaria as a problem but make weak or uncoordinated efforts to solve it. A persistent and systematic approach to problems pays off.

- Focus and reliance on evidence: Malawi has been able to look for what works, to convince donor partners using evidence of what works, and to use the evidence of what works to elicit funds from donor partners. The GOM has adopted the reliance on evidence and problembased solutions as a method of work.

- Strategic partnership: The GOM has demonstrated that partnerships based on evidence and on what works and using that evidence to convince donors are strategic. It leads to an effective and long-term partnership to address a problem such as malaria.

- Political will and action: The GOM has taken determined and consistent decisions and actions to support MIP interventions. These decisions include the subsidy of and removal of tariffs on ITNs. This type of policy is critical in the success of social programs such as MIP interventions.

- The vision to end malaria: There is a vision in Malawi to eliminate or reduce malaria to a level where it is no longer a public health problem within 20 to 30 years. In other words, the end result and strategy have been harmonized. This approach not only eliminates the worry about sustainability, but it demonstrates a determined effort to deal with a problem using existing means.

\section{b) Lessons from Development Donor Partners}

- Convinced by evidence: Development partners have shown remarkable cooperation with the GOM on malaria as a national priority, leading to an unprecedented high level of funding. This result has come about because the donors have been convinced by the evidence of the problem and of what works.

\section{c) Lessons from BIMI}

- Problem-based approach: BIMI demonstrated that a problem-based and problem-solving approach is effective and should be the basis of national policies. It is important to identify for what works and avoid ready-made solutions. 
- Integration: A standalone project does not deliver effectively without employing the national delivery systems. The BIMI project demonstrated that it is important to integrate their efforts with the national health system and work with the MOH staff.

- From pilot to full-scale program: The usefulness of a project can be seen when its benefits and lessons are translated into policy and implemented full scale at the national level. This achievement is easily possible if the evidence of project innovations is clear and stakeholders have fully participated in their formulation. Once the policy has been adopted, project activities and benefits are sustained by becoming routine services.

\section{(d) Lessons about sustainability}

$\checkmark$ Desired results and routine: Sustainability is the continuation and expansion of project activities and benefits, becoming routine services, and being able to attract attention and resources from donors based on the ability of the project to produce desired results.

$\checkmark$ Integration: Sustainability is ensured when a project or program is integrated with and implemented through the national health system.

$\checkmark$ Strategic partnership: Sustainability of MIP is having a strategic partnership with donors, with a long-term vision of 20 to 30 years with the aim of this partnership leading to the elimination of malaria as a public health problem.

$\checkmark$ Persistence and long-term vision: Ultimately, it pays for a country or government to be persistent with a long-term vision in addressing a priority national problem such as malaria.

$\checkmark$ Evidence: Evidence is key in understanding a problem, in finding a solution to the problem, and in proving that the solution works.

$\checkmark$ Simplified guidelines: It is critical to have simple, well-communicated, well-understood, and easy-to-monitor policies and guidelines.

A number of conclusions can be drawn from the BIMI and Malawi experience.

- There has been remarkable progress with MIP interventions in Malawi as a whole, with many of the initiatives having originated from the BIMI project. The second SP doses, ITN usage by pregnant women, and the knowledge of mothers on SP and ITNs are high and increasing. In addition, the MIP products are available and easily accessible.

- There is ample evidence that MIP interventions went quickly from being pilot to routine national programs. It started in one district and triggered off a chain of events that led to rapid scaling-up of the interventions.

- Although MIP products are still largely publicly provided, there is an increasing trend of availability and access to the products in the private sector. This demonstrates increasing 
demand and willingness to pay for the products, which are critical for the future sustainability of the program.

- Key factors for continuation and scaling-up can be attributed to the innovations from BIMI, the partnership between GOM and donors, and a conducive policy environment created by GOM. Fifth, future sustainability of the MIP depends on maintaining the demand for the MIP products, a long-term partnership with development partners, problem- and evidence-based solutions, organizational capacity and viability, and political stability. 


\section{REFERENCES}

Central Bureau of Statistics (CBS) [Kenya], Ministry of Health (MOH) [Kenya], and ORC Macro. 2004. Kenya Demographic and Health Survey2003. Calverton, Maryland: CBS, $\mathrm{MOH}$, and ORC Macro.

Goodman, C.A., P.G. Coleman, and A.J. Mills. 2001. The cost effectiveness of antenatal malaria prevention in Sub-Saharan Africa, American Journal of Tropical Medicine and Hygiene 64(1,2): 45-56.

Ministry of Health (MOH), Kenya. 2001. National Malaria Control Strategy 2001-2010. Division of Malaria Control.

-, Kenya. 2003. National Guidelines for Diagnosis, Treatment and Prevention of Malaria for Health Workers. Division of Malaria Control.

— Kenya. 2005. Insecticide Treated Net Policy Guidelines. Division of Malaria Control.

Ministry of Health (MOH), Malawi. 2004a. "The coverage and utilization of insecticide treated nets and malaria prevention and treatment practices at the community level in Malawi," Government of Malawi, Zomba.

— Malawi. 2004b. Joint Programme of Work for Health Sector Wide Approach SWAP (20042010), MOH, Malawi.

—, Malawi. 2004c. “Taking Stock of Malawi’s Progress Toward Abuja Targets. National Malaria Survey, 2004. Lilongwe, Malawi.

National Co-coordinating Agency for Population and Development (NCAPD), Ministry of Health (MOH), Central Bureau of Statistics (CBS), and ORC Macro. 2005. Kenya Service Provision Assessment Survey 2004. Nairobi, Kenya: National Co-coordinating Agency for Population and Development, Ministry of Health, Central Bureau of Statistics, and ORC Macro.

National Statistical Office (Malawi) and ORC Macro. 2000. Malawi Demographic and Health Survey 2000. Zomba, Malawi and Calverton, Maryland USA.

Olenja, J., J. Mwanza, and S. Andolo. 2003. Final evaluation of Bungoma District Malaria Initiative (BDMI). Report prepared for BDMI and USAID/Kenya.

Parise, E.M. et al. 1998. "Efficacy of sulfhadoxine-pyremethamine for prevention of placental malaria in an area of Kenya with high prevalence if malaria and Human Immunodeficiency Virus Infection," American Journal of Tropical Medicine and Hygiene 59(5), 813-822.

Sarriot, E.G., P.J. Winch, L.J. Ryan, J. Bowie, M. Kouletio, E. Swedberg, K. LeBan, J. Edison, R. Welch, and M.C. Pacque. 2004. "A methodological approach and framework for sustainability assessment in NGO-Implemented primary health care programs," International Journal of Health Planning and Management 2004 19: 23-41. 
Seltzer, J.R. 2002. Findings and Lessons Learned from the Bungoma District Malaria Initiative 1989-2002. Interim report prepared under the auspices of Population Reference Bureau, MEASURE Communication, for BDMI and USAID/Kenya.

Steketee, R.W., B.L. Nahlen, M.E. Parise, and C. Menendez. 2001. The Burden of Malaria in Pregnancy in Malaria Endemic Areas. American Journal of Tropical Medicine and Hygiene 64(1,2)S, 28-35.

World Health Organization (WHO). 2003. Strategic framework for malaria control during pregnancy in the WHO African Region. Geneva, World Health Organization. 